\title{
Disguised fasting for fasting blood glucose determination: how about its actual incidence?
}

\author{
Viroj Wiwanitkit
}

Received: 4 February 2011 / Accepted: 20 June 2011 / Published online: 20 July 2011

(C) Research Society for Study of Diabetes in India 2011

Sir, fasting blood glucose determination is a widely used endocrine and metabolic testing in medical practice. This test is a routine investigation in follow-up evaluation of diabetes mellitus in many countries. The critical point for performing this test is a good patient preparation, fasting [1]. The problems arising out of improper fasting practices can be expected. Here, the author would like to draw attention to the problem of disguised fasting in actual clinical practice. The author verbally inquired into the fasting practice followed by 300 diabetic patients who visited to the diabetic clinic for follow-up. All cases got the fasting blood determination at a certified clinical pathology laboratory. Of interest, the author found that 12 patients $(4 \%)$ reported that they did not perform correct fasting (three with no fasting and nine with incorrect fasting). Hence, a considerable rate of disguising of fasting sample can be seen. This can affect treatment strategy if the general practitioners do not make a note of this fact. The improper decision may be taken to adjust the antidiabetic regimen corresponding to the disguised high fasting blood glucose. In fact, although the labora- tory has good quality system, it cannot correct the preanalytical problem such as poor patient preparation [2]. Since the checking for fasting state is usually verbal, the disguising can be expected. Due to this reason, the actual rate of disguising might be higher than $4 \%$. Some patients might also disguise to both laboratory and physician. The practice of using hemoglobin A1C for follow-up of diabetics, resolves such an issue completely [3].

\section{References}

1. Brigden ML, Heathcote JC. Problems in interpreting laboratory tests. What do unexpected results mean? Postgrad Med. 2000;107:145-6, 151-2, 155-8.

2. Wiwanitkit V. Types and frequency of preanalytical mistakes in the first Thai ISO 9002:1994 certified clinical laboratory, a 6-month monitoring. BMC Clin Pathol. 2001;1:5.

3. Russell-Minda E, Jutai J, Speechley M, Bradley K, Chudyk A, Petrella $\mathrm{R}$. Health technologies for monitoring and managing diabetes: a systematic review. J Diabetes Sci Technol. 2009;3:1460-71.

\footnotetext{
V. Wiwanitkit $(\bowtie)$

Wiwanitkit House,

Bangkhae,

Bangkok, Thailand 10160

e-mail: wviroj@yahoo.com
} 